\title{
A bio-psychosocial intervention program for improving quality of life in breast cancer survivors: Results of a prospective randomized trial
}

\author{
Janine Pettiford ${ }^{1}$, Sharon Felts ${ }^{1}$, Edna Wischkaemper ${ }^{1}$, Debbie Miller ${ }^{1}$, Sybil Crawford ${ }^{2}$, Rakhshanda Layeequr \\ Rahman*1 \\ ${ }^{1}$ Breast Center of Excellence, Texas Tech University Health Sciences Center, Amarillo, United States \\ ${ }^{2}$ Division of Preventive and Behavioral Medicine, Department of Medicine, University of Massachusetts Medical School, \\ Worcester, United States
}

Received: March 7, 2016

DOI: $10.5430 /$ jst.v6n2p48
Accepted: May 23, 2016

Online Published: June 11, 2016

\begin{abstract}
Background: Given the 3.1 million breast cancer survivors in America, quality of life (QoL) is a vital issue. Bio-psychosocial milieu of survivorship is increasingly important. This study assesses the impact of bio-psychosocial intervention (BPSI) on the QoL of breast cancer survivors utilizing Functional Assessment of Cancer Therapy - Breast (FACT-B) instrument.

Methods: A prospective randomized trial was designed; intervention arm included a 4-hour BPSI coping skills class; control arm received standard of cancer (SOC) and follow up care. Women diagnosed within 2 years of study initiation were eligible. Sample size was based on 8-point difference in FACT-B score, $90 \%$ power, $5 \%$ type I error, and $20 \%$ attrition. FACT-B questionnaire was administered to all patients at baseline and at 6-month intervals. SAS 9.3 software was used to analyze data using Chi-square test for categorical and Wilcoxon rank sum for ordinal data; linear mixed modeling was used for longitudinal analysis.

Results: One hundred and three of $120(86 \%)$ patients were available for analysis. Forty-seven patients were in BSPI arm, and 56 received SOC. For BPSI arm $v s$. SOC arm, the median (interquartile) age [60 $(52,68) v s .58(52,68)$ yrs. $P=.9135]$, cancer-stage (0: $1: 2: 3=11 \%: 41 \%: 35 \%: 13 \%$ vs. $18 \%: 46 \%: 22 \%: 15 \%, P=.4645$ ), and biology (triple-negative: HER2+: ER+ = 9\%: $74 \%: 17 \%$ vs. $8 \%: 72 \%: 20 \%, P=.8454)$, respectively, was similar. Mean (SE) FACT-B scores in BPSI vs. SOC arms at 6 months and 1 year were $115.1(2.2) v s .114 .6(2.0)(P=.8731)$ and $124.7(2.8) v s .101 .4(2.4)(P=.0001)$. The inter-group difference significantly expanded at 1 year $(P=.0001)$. The 12-month difference persisted when confounding baseline variables were adjusted for in in multivariate modeling.

Conclusion: BPSI coping skills class significantly improved the QoL of breast cancer survivors by one year post-intervention time point.
\end{abstract}

Key Words: Survivorship, Quality of life, Bio-psychosocial feedback

\section{BACKGROUND}

An individual is considered a cancer survivor from the time of diagnosis, through the balance of his/her life. Family members, friends, and caregivers are also impacted by the survivorship experience and are therefore included in this definition of cancer survivor. ${ }^{[1,2]}$ Just including the number of treated patients, as of January 1, 2014, there are 3.1 million breast cancer survivors in United States. ${ }^{[3]}$ This growing

\footnotetext{
*Correspondence: Rakhshanda Layeequr Rahman; Email: rakhshanda.rahman@ttuhsc.edu; Address: Texas Tech University Health Sciences Center, Breast Center of Excellence, 1400 Coulter, Amarillo, TX 79106, United States.
} 
number of breast cancer survivors and co-survivors is attributable to improved survival rates. ${ }^{[4]}$ Moreover, women under the age of 50 are estimated to represent $25 \%$ of this group. ${ }^{[5,6]}$ Screening mammography and improvements in treatment have resulted in a substantial decrease in mortality which explains why more women diagnosed at a younger age are becoming long-term survivors. Consequently, quality of life (QoL) has become increasingly important in the contemporary management of breast cancer. ${ }^{[7]}$ It has been shown that multimodality breast cancer treatment has longterm bio-psychosocial consequences. ${ }^{\left[{ }^{[8}, 9\right]}$ Therefore, specific proposals are being put forth for long-term survivorship care planning. ${ }^{[10]}$ However, these proposals focus on long-term treatment related physical complications, and early detection of recurrence. In addition, a survey of providers reflects the lack of involvement of many providers in psychosocial aspects of care and underscores the need for coordinated strategies to impact QoL. ${ }^{[11]}$

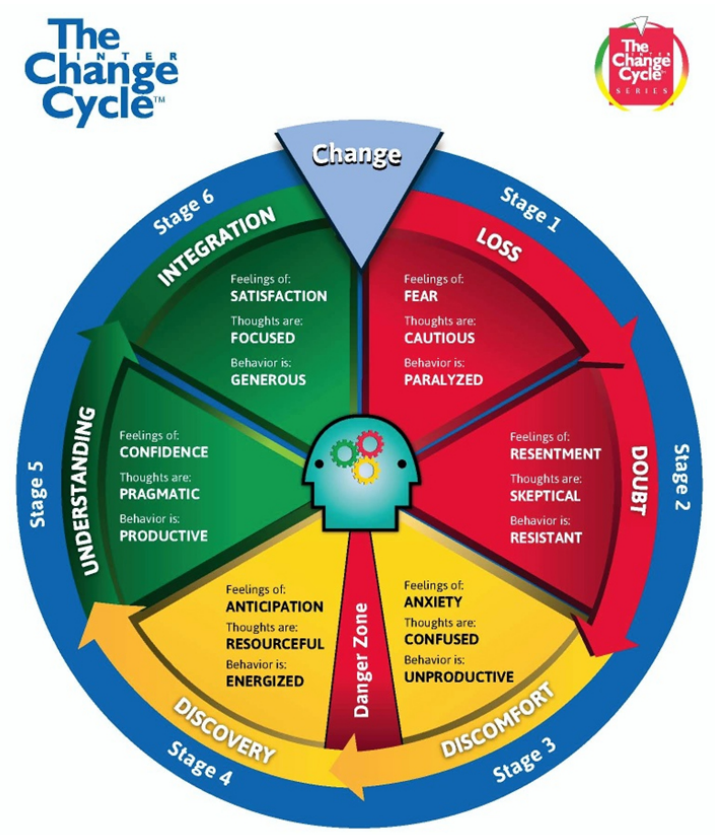

Figure 1. The Change Cycle ${ }^{\mathrm{TM}}$ model-reproduced with permission from www. Changecycle.com

Whereas, several disciplines dealing with physical aspects of disease have come together to provide multidisciplinary care for breast cancer patients, BPSI has not become a part of this care. There are two explanations for this phenomenon: 1) lack of high quality evidence favoring a specific intervention that could be easily replicated, ${ }^{[12]}$ and 2) cultural and stigma-related barriers to psycho-oncology counseling. ${ }^{[13,14]}$ It seems plausible that a BPSI program that is impactful, reproducible and removes the stigma associated with "psych" referral, may enhance patient participation and improve QoL of survivors. We investigated the impact of a specific BPSI program on QoL of breast cancer survivors.

\section{Methods}

\subsection{Study design}

A prospective randomized, Institutional Review Board approved trial was conducted to evaluate the impact of a BPSI program compared with standard of care (SOC). Both groups of subjects were asked to complete the FACT-B QoL questionnaire at enrollment and every 6 months for 2 years. One year results are being presented.

\subsection{Proposed intervention}

The specific BPSI chosen for this study was an adaptation of "The Change Cycle TM" model by Ann Salerno (see Figure 1). ${ }^{[15]}$ The circle represents the cyclical nature of each change experienced by the human brain and depicts the six sequential and predictable stages of this experience; namely: Loss, Doubt, Discomfort, Discovery, Understanding, and Integration. "The Change Cycle TM" uses the colors of a traffic light to signal that the stages mirror our reaction to the traffic light. The survivor training involved a 4-hour coping skills class once a month, utilizing the Change Cycle ${ }^{\mathrm{TM}}$ model administered by certified facilitators. The certification involves a two day course whereby participants learn the conceptual content, resource materials, and logistics of class administration. In our study, this class was offered by 2 certified facilitators (one English-speaking, one Spanishspeaking) with a background in counseling and human development/training. The class focuses on the diagnosis of breast cancer representing a major life change; the structure of the class includes a profile of each stage to gain perspective and understanding, teaching personal change skills for each stage and a strategy for movement to the next stage. The overall design follows an "act as if" philosophy, guiding participants through each stage of the cycle. The introduction includes an overview of "The Change Cycle TM" and its concepts, as well as the administration of "The Change Cycle Locator" to assist participants in identifying the stage of their personal change-experience. The approach is both didactic and experiential. Participants learn skills to: 1) identify the six stages of change and their affect at the mental, emotional and behavioral levels, 2) work in concert with the processes of the brain as it encounters new and changing situations, 3) pinpoint what stage they are in with regard to a specific change they are experiencing, brought about by diagnosis, treatment, or survivorship issues, 4) differentiate between proactive and reactive change situations and understand the best practices for successful change, 5) build new and more resourceful strategies for self-management, and 6) have a perspective 
for identifying patterns of thoughts, feelings, and behaviors associated with their experience. Patients randomized to the intervention arm attended at least one group-session and had an option for follow up with a one-on-one session if desired. Co-survivors (family members and friends or other support members identified by the patient as support system through cancer journey ${ }^{[16]}$ ) of these patients were encouraged to attend the class as well. Comparison arm received routine multidisciplinary breast cancer care.

\subsection{Primary outcome measure}

Functional Assessment of Cancer Therapy (FACT) quality of life questionnaire was developed in early 1990 's , $^{[17]}$ the modified and validated score specific to breast cancer patients - FACT-B was chosen as the primary outcome measure. ${ }^{[18]}$ FACT-B is a 44-item self-report instrument designed to measure multidimensional QoL in patients with breast cancer.

\subsection{Eligibility criteria}

Women with an established diagnosis of breast cancer, diagnosed after January 2010, and including newly diagnosed patients were eligible to participate.

\subsection{Exclusion criteria}

Women declining randomization were excluded.

\subsection{Sample size calculation}

A priori sample size calculations were based on primary outcome of QoL, as measured by the FACT-B questionnaire. Specifically, to detect a clinically important difference in overall QoL between groups or change over time of 8 units (standard deviation of change in FACT-B over 12 months = 10 units), with $90 \%$ power and 5\% type I error (two-tailed), a minimum of 40 women per group were required. Sample size was inflated by $20 \%$ to allow for attrition and an additional $20 \%$ for multivariable modeling, yielding our target sample size of 60 survivors per group.

\subsection{Recruitment process}

The patients were introduced to the trial when seen in the breast cancer or survivorship clinic. Typically the trial was offered after surgery but within 2 years of diagnosis. Study was advertised by posting on the Breast Center of Excellence web site, and flyers.

\subsection{Randomization}

Following signed informed consent and base-line assessment, women were randomized individually via a computer generated, unblocked, sequence of random numbers to obtain similar numbers of survivors in the BPSI arm and the SOC arm. No stratification factors were used for randomization and a multivariate analysis was planned to address the potential confounders such as endocrine therapy, chemotherapy, participation in support groups, and treatment status at the time of enrollment etc.

\subsection{Data collection, timing and outcomes}

Both BPSI and SOC arms were given a FACT-B Survey, at baseline and at 6-monthly intervals (planned for 2 years). Patient and cancer related variables collected as baseline included age, insurance status, type and stage of cancer at the time of diagnosis ( 0 , I, II, III, IV), biological markers $(+,-)$, use of chemotherapy (yes/no), use of radiation therapy (yes/no), endocrine treatment (yes/no), type of surgery and reconstruction (yes/no) and complications related to treatment.

\subsection{Statistical analysis}

Retention rate was calculated by dividing the number of participants who completed follow-up questionnaires by the number who completed baseline survey. Baseline characteristics for the BPSI arm and the SOC arm were compared using mean and standard deviation for normally-distributed, continuous outcomes; median, minimum and maximum for non-parametric continuous data; ${ }^{[19]}$ and proportions for categorical outcomes.

Randomization groups were compared regarding baseline characteristics using chi-square tests for categorical variables and Wilcoxon rank sum for continuous variables. The difference between randomized groups in follow-up quality of life was analyzed according to intention-to-treat principles, using linear mixed models ${ }^{[20]}$ as a function of randomization group, follow-up time point (6 and 12 months), and group by time interaction, controlling for the baseline outcome value to address possible regression to the mean. ${ }^{[21]}$ These unadjusted results were compared with results adjusting for all baseline covariates, and with results adjusting for a reduced set of baseline variables related to the outcome being modeled, identified using backward elimination. ${ }^{[19]}$ SAS 9.3 software (SAS Institute, Cary, NC) was used for all analyses.

\section{RESULTS}

Of the 120 patients, $60(50 \%)$ were randomized to BPSI arm; $60(50 \%)$ were in SOC arm. Thirteen (22\%) patients from the BPSI arm and $4(6 \%)$ patients from the SOC arm dropped out after randomization, and are excluded from analyses. Of the remaining 103 patients, $93.2 \%$ provided 12 -month data (91.5\% for BPSI, $94.6 \%$ for SOC); 12-month participation was not significantly related to randomization group $(P=$ $.70)$ or to any FACT-B scales $(P>.10)$. The internal consistency for total FACT-B score, measured by Cronbach's 
alpha score, was 0.91 or higher at all three time points. The baseline characteristics of the two groups are depicted in Table 1. Most baseline characteristics were similar across both arms. There were significant differences between the two arms in terms of insurance status, systemic therapy, and surgery. Twenty-eight (64\%) had commercial insurance in
BPSI arm vs. $22(42 \%)$ in SOC arm $(P=.041) ; 25(56 \%)$ patients received chemotherapy in BPSI arm vs. $16(30 \%)$ in SOC $\operatorname{arm}(P=.014)$; and $40(85 \%)$ patients had lumpectomy in BPSI arm vs. $17(31 \%)$ receiving mastectomy in SOC arm $(P=.011)$.

Table 1. Baseline characteristics

\begin{tabular}{|c|c|c|c|}
\hline & BPSI $(n=47)$ & SOC $(n=56)$ & $P$ value \\
\hline Age median (interquartile) years & $60(52,68)$ & $58(52,68)$ & .9921 \\
\hline \multicolumn{4}{|l|}{ Insurance n (\%) } \\
\hline Commercial & $28(63.6)$ & $22(41.5)$ & \multirow{2}{*}{.0413} \\
\hline Underinsured & $16(36.4)$ & $31(58.5)$ & \\
\hline \multicolumn{4}{|l|}{ Stage n (\%) } \\
\hline 0 & $5(10.9)$ & $10(18.2)$ & \multirow{5}{*}{.4645} \\
\hline 1 & 19 (41.3) & 25 (45.5) & \\
\hline 2 & $16(34.8)$ & $12(21.8)$ & \\
\hline 3 & $6(13.0)$ & $8(14.6)$ & \\
\hline 4 & 0 & 0 & \\
\hline \multicolumn{4}{|l|}{ Biological risk status n (\%) } \\
\hline Low risk ER positive & $32(74.4)$ & $39(72.2)$ & \multirow{3}{*}{.8454} \\
\hline High risk triple negative & $4(9.3)$ & $4(7.4)$ & \\
\hline Hi risk HER 2 positive & 7 (16.3) & $11(20.4)$ & \\
\hline \multicolumn{4}{|l|}{ Chemotherapy n (\%) } \\
\hline Yes & $25(55.6)$ & $16(30.2)$ & \multirow{2}{*}{.0141} \\
\hline No & $20(44.4)$ & $37(69.8)$ & \\
\hline \multicolumn{4}{|l|}{ Radiation n (\%) } \\
\hline Yes & 40 (90.9) & $42(77.8)$ & \multirow{2}{*}{.1024} \\
\hline No & $4(9.1)$ & $12(22.2)$ & \\
\hline \multicolumn{4}{|l|}{ Surgery n (\%) } \\
\hline Unilateral lumpectomy & $40(85.1)$ & $31(56.4)$ & \multirow{4}{*}{.0110} \\
\hline Bilateral lumpectomy & $0(0.0)$ & $2(3.6)$ & \\
\hline Unilateral mastectomy & $4(8.5)$ & $17(30.9)$ & \\
\hline Bilateral mastectomy & $3(6.4)$ & $5(9.1)$ & \\
\hline \multicolumn{4}{|l|}{ Reconstruction n (\%) } \\
\hline Yes & $8(17.0)$ & $9(16.4)$ & \multirow{2}{*}{1.0000} \\
\hline No & $39(83.0)$ & $46(83.6)$ & \\
\hline \multicolumn{4}{|c|}{ Treatment status ${ }^{*}$ at enrollment n (\%) } \\
\hline During treatment & $17(36.2)$ & $25(44.6)$ & \multirow{3}{*}{.6812} \\
\hline Within 6 months of completion & $20(42.6)$ & 21(37.5) & \\
\hline Within 1 year of completion & $10(21.3)$ & 10(17.9) & \\
\hline \multicolumn{4}{|l|}{ Support group participation n (\%) } \\
\hline Yes & 7 (14.9) & $8(14.3)$ & \multirow{2}{*}{1.0000} \\
\hline No & $40(85.1)$ & 48 (85.7) & \\
\hline
\end{tabular}

Note. ER = Estrogen Receptor; HER 2 = Human Epidermal Growth Factor Receptor 2. ${ }^{*}$ Treatment status considers surgery, chemotherapy and radiation therapy, not endocrine therapy since it is a long-term treatment.

\subsection{Unadjusted longitudinal analysis}

As seen in Table 2, BPSI and SOC participants did not differ significantly at baseline on any of the FACT-B subscales.

Published by Sciedu Press
Table 2 also depicts the difference in QoL as measured by mean FACT-B scores between the BPSI and SOC arms at 6-month and 1-year intervals, from linear mixed models ad- 
justing only for corresponding baseline scores. This table accounts for within-woman change and adjusts for baseline scores so that each woman represents her own control over time (since some baseline factors such as insurance status were different in two groups). Overall, at 6 months, mean scores for all FACT-B subscales were higher than at baseline, but there were no statistically significant differences between the BPSI and SOC arms in mean scores. In contrast, at 1 year, the means in all sub-scales except "additional concerns" diverged for the two groups, with significantly better wellbeing in the BPSI participants than in the SOC participants $(P<.0001)$. Moreover, the between-group difference was significantly larger than the corresponding difference at 6 months $(P<.0001)$ denoting that the difference in the two arms could not simply be due to natural accommodation during cancer survivorship.

Table 2. Comparison of BPSI and SOC participants regarding change in FACT-B at 6 and 12 months, adjusting only for baseline outcome value and accounting for within-woman correlation

\begin{tabular}{|c|c|c|c|c|c|c|c|c|c|c|}
\hline \multirow{3}{*}{$\begin{array}{l}\text { Outcome: higher } \\
\text { values are better }\end{array}$} & \multirow{2}{*}{\multicolumn{2}{|c|}{$\begin{array}{l}\text { Baseline } \\
\text { Mean (SE) }\end{array}$}} & \multirow{3}{*}{$P$-value ${ }^{*}$} & \multirow{2}{*}{\multicolumn{2}{|c|}{$\begin{array}{l}\text { 6-month } \\
\text { Mean Change } \\
\text { Since Baseline (SE) }\end{array}$}} & \multirow{3}{*}{$P$-value } & \multicolumn{3}{|c|}{ 12-month } & \multirow{3}{*}{$\begin{array}{l}\text { Interaction } \\
\boldsymbol{P} \text {-value }^{\#}\end{array}$} \\
\hline & & & & & & & \multicolumn{2}{|c|}{ Since Baseline (SE) } & \multirow[t]{2}{*}{$P$-value } & \\
\hline & BPSI & SOC & & BPSI & SOC & & BPSI & SOC & & \\
\hline Physical well-being & $\begin{array}{l}20.38 \\
(0.73)\end{array}$ & $\begin{array}{l}21.48 \\
(0.67)\end{array}$ & .1887 & $\begin{array}{l}1.10 \\
(0.59)\end{array}$ & $\begin{array}{l}1.43 \\
(0.53)\end{array}$ & .6823 & $\begin{array}{l}3.31 \\
(0.74)\end{array}$ & $\begin{array}{l}-2.61 \\
(0.67)\end{array}$ & $<.0001$ & $<.0001$ \\
\hline Social well-being & $\begin{array}{l}22.03 \\
(0.73)\end{array}$ & $\begin{array}{l}21.88 \\
(0.73)\end{array}$ & .9578 & $\begin{array}{l}0.92 \\
(0.68)\end{array}$ & $\begin{array}{l}1.64 \\
(0.61)\end{array}$ & .4359 & $\begin{array}{l}3.25 \\
(0.72)\end{array}$ & $\begin{array}{l}-2.71 \\
(0.65)\end{array}$ & $<.0001$ & $<.0001$ \\
\hline Emotional well-being & $\begin{array}{l}17.51 \\
(0.67)\end{array}$ & $\begin{array}{l}18.37 \\
(0.58)\end{array}$ & .3021 & $\begin{array}{l}1.93 \\
(0.48)\end{array}$ & $\begin{array}{l}1.59 \\
(0.44)\end{array}$ & .5951 & $\begin{array}{l}3.95 \\
(0.66)\end{array}$ & $\begin{array}{l}-1.57 \\
(0.60)\end{array}$ & $<.0001$ & $<.0001$ \\
\hline Functional well-being & $\begin{array}{l}19.09 \\
(0.92)\end{array}$ & $\begin{array}{l}19.84 \\
(0.81)\end{array}$ & .5382 & $\begin{array}{l}2.98 \\
(0.67)\end{array}$ & $\begin{array}{l}1.90 \\
(0.61)\end{array}$ & .2380 & $\begin{array}{l}4.54 \\
(0.73)\end{array}$ & $\begin{array}{l}-1.20 \\
(0.66)\end{array}$ & $<.0001$ & .0003 \\
\hline $\begin{array}{l}\text { Additional breast } \\
\text { cancer-specific } \\
\text { concerns }\end{array}$ & $\begin{array}{l}26.07 \\
(1.04)\end{array}$ & $\begin{array}{l}26.36 \\
(0.90)\end{array}$ & .6679 & $\begin{array}{l}0.44 \\
(0.88)\end{array}$ & $\begin{array}{l}1.00 \\
(0.78)\end{array}$ & .6402 & $\begin{array}{l}2.13 \\
(0.91)\end{array}$ & $\begin{array}{l}1.65 \\
(0.82)\end{array}$ & .7004 & .3750 \\
\hline FACT-G & $\begin{array}{l}79.00 \\
(2.58)\end{array}$ & $\begin{array}{l}81.57 \\
(1.95)\end{array}$ & .5613 & $\begin{array}{l}7.05 \\
(1.60)\end{array}$ & $\begin{array}{l}6.48 \\
(1.45)\end{array}$ & .7905 & $\begin{array}{l}15.11 \\
(2.38)\end{array}$ & $\begin{array}{l}-8.10 \\
(2.14)\end{array}$ & $<.0001$ & $<.0001$ \\
\hline FACT-B & $\begin{array}{l}105.74 \\
(3.37)\end{array}$ & $\begin{array}{l}108.28 \\
(2.62)\end{array}$ & .6125 & $\begin{array}{l}7.53 \\
(2.22)\end{array}$ & $\begin{array}{l}7.05 \\
(1.97)\end{array}$ & .8731 & $\begin{array}{l}17.12 \\
(2.62)\end{array}$ & $\begin{array}{l}-6.08 \\
(2.36)\end{array}$ & $<.0001$ & $<.0001$ \\
\hline
\end{tabular}

Note. ${ }^{*}$ From Wilcoxon rank sum test; ${ }^{\#} P$-value for time point $\times$ treatment arm, i.e., whether BPSI versus SOC difference differs at 6 and 12 months.

\subsection{Multivariate analysis adjusting for covariates}

Covariate-adjustment particularly with variables that were different at baseline is presented in Table 3; these factors generally had little impact on between-group differences in 6-month and 1-year QoL, as patterns of covariate-adjusted means and $P$-values for between-group differences were very similar to corresponding results in Table 2 . The single exception was a statistically significant difference at 6 months in physical well-being [mean change since baseline for BPSI vs. $\mathrm{SOC}=0.04$ (0.60) vs. $2.47(0.51), P=.0051]$ when all Table 1 characteristics were included as predictors in the multivariate model. Only 85 participants were included in these analyses, however, due to missing covariate data, and women in the SOC group with low physical well-being were disproportionately omitted. Backward elimination retained only surgery type and support group participation as covariates, yielding a larger sample size (100 women); the resulting 6month estimates were 0.77 (0.60) for BPSI vs. $1.69(0.54)$ for SOC $(P=.27)$, consistent with results in Table 2 . Results for other QoL outcomes adjusting for the subset of statistically significant covariates identified using backward elimination also were consistent with Table 2 (data not shown).

\section{Discussion}

Traditional approach to evidence-based-practice in oncology has focused on development of strategies and therapies that directly impact survival. This approach assumes, appropriately so in many instances, that "survival" i.e. the quantity of life is the most important outcome measure. As a result the approaches that do not directly impact "survival" are unlikely to become a part of "standard of care". Continuing with this tradition, a lot of work on psychotherapy and psycho-oncology has focused on survival. ${ }^{[22]}$ The majority of such studies have focused on breast cancer survivors; many have attempted to define the mechanisms involved in improving survival with psychosocial intervention including the hypothalamic-pituitary axis, the immune system, disruption of other circadian rhythms such as sleep/activity, the sympathetic-adrenal-medullary system, and the relationship between stress and p53 gene expression. ${ }^{[23]}$ However, there 
is significant controversy around whether or not BPSI im- equate sample sizes. Coyne et al. report that trials in which proves survival. ${ }^{[24]}$ This has resulted from factors including "survival" was the "a priori" endpoint for psycho-therapeutic lack of consistency in definition of intervention, ${ }^{[25]}$ and inad- interventions have not shown to impact median survival. ${ }^{[26]}$

Table 3. Comparison of BPSI and SOC participants regarding change in FACT-B at 6 and 12 months, adjusting for baseline outcome value and all baseline covariates, and accounting for within-woman correlation; 85 participants with complete covariate data

\begin{tabular}{|c|c|c|c|c|c|c|c|c|c|c|}
\hline \multirow{3}{*}{$\begin{array}{l}\text { Outcome: higher } \\
\text { values are better }\end{array}$} & \multicolumn{3}{|c|}{ Baseline } & \multicolumn{3}{|c|}{ 6-month } & \multicolumn{3}{|c|}{ 12-month } & \multirow{3}{*}{$\begin{array}{l}\text { Interaction } \\
P \text {-value }\end{array}$} \\
\hline & \multicolumn{2}{|c|}{ Mean (SE) } & \multirow[t]{2}{*}{$P$-value ${ }^{*}$} & \multicolumn{2}{|c|}{$\begin{array}{l}\text { Mean Change } \\
\text { Since Baseline (SE) }\end{array}$} & \multirow[t]{2}{*}{$P$-value } & \multicolumn{2}{|c|}{$\begin{array}{l}\text { Mean Change } \\
\text { Since Baseline (SE) }\end{array}$} & \multirow[t]{2}{*}{$P$-value } & \\
\hline & BPSI & SOC & & BPSI & SOC & & BPSI & SOC & & \\
\hline Physical well-being & $\begin{array}{l}20.38 \\
(0.73)\end{array}$ & $\begin{array}{l}21.48 \\
(0.67)\end{array}$ & .1887 & $\begin{array}{l}0.04 \\
(0.60)\end{array}$ & $\begin{array}{l}2.47 \\
(0.51)\end{array}$ & .0051 & $\begin{array}{l}2.75 \\
(0.82)\end{array}$ & $\begin{array}{l}-2.18 \\
(0.70)\end{array}$ & $<.0001$ & $<.0001$ \\
\hline Social well-being & $\begin{array}{l}22.03 \\
(0.73)\end{array}$ & $\begin{array}{l}21.88 \\
(0.73)\end{array}$ & .9578 & $\begin{array}{l}1.37 \\
(0.68)\end{array}$ & $\begin{array}{l}2.24 \\
(0.58)\end{array}$ & .3624 & $\begin{array}{l}2.69 \\
(0.83)\end{array}$ & $\begin{array}{l}-2.14 \\
(0.70)\end{array}$ & $<.0001$ & $<.0001$ \\
\hline Emotional well-being & $\begin{array}{l}17.51 \\
(0.67)\end{array}$ & $\begin{array}{l}18.37 \\
(0.58)\end{array}$ & .3021 & $\begin{array}{l}1.43 \\
(0.59)\end{array}$ & $\begin{array}{l}2.20 \\
(0.51)\end{array}$ & .3605 & $\begin{array}{l}3.66 \\
(0.80)\end{array}$ & $\begin{array}{l}-1.20 \\
(0.68)\end{array}$ & $<.0001$ & $<.0001$ \\
\hline Functional well-being & $\begin{array}{l}19.09 \\
(0.92)\end{array}$ & $\begin{array}{l}19.84 \\
(0.81)\end{array}$ & .5382 & $\begin{array}{l}2.35 \\
(0.86)\end{array}$ & $\begin{array}{l}1.94 \\
(0.74)\end{array}$ & .7308 & $\begin{array}{l}4.01 \\
(0.82)\end{array}$ & $\begin{array}{l}-1.35 \\
(0.69)\end{array}$ & $<.0001$ & .0009 \\
\hline $\begin{array}{l}\text { Additional breast } \\
\text { cancer-specific } \\
\text { concerns }\end{array}$ & $\begin{array}{l}26.07 \\
(1.04)\end{array}$ & $\begin{array}{l}26.36 \\
(0.90)\end{array}$ & .6679 & $\begin{array}{l}0.45 \\
(1.10)\end{array}$ & $\begin{array}{l}1.34 \\
(0.94)\end{array}$ & .5646 & $\begin{array}{l}2.70 \\
(1.04)\end{array}$ & $\begin{array}{l}1.45 \\
(0.89)\end{array}$ & .4011 & .0850 \\
\hline FACT-G & $\begin{array}{l}79.00 \\
(2.58)\end{array}$ & $\begin{array}{l}81.57 \\
(1.95)\end{array}$ & .5613 & $\begin{array}{l}5.78 \\
(1.80)\end{array}$ & $\begin{array}{l}8.38 \\
(1.54)\end{array}$ & .3065 & $\begin{array}{l}13.87 \\
(2.60)\end{array}$ & $\begin{array}{l}-7.29 \\
(2.21)\end{array}$ & $<.0001$ & $<.0001$ \\
\hline FACT-B & $\begin{array}{l}105.74 \\
(3.37)\end{array}$ & $\begin{array}{l}108.28 \\
(2.62)\end{array}$ & .6125 & $\begin{array}{l}7.08 \\
(2.32)\end{array}$ & $\begin{array}{l}8.25 \\
(2.01)\end{array}$ & .7058 & $\begin{array}{l}17.08 \\
(2.66)\end{array}$ & $\begin{array}{l}-5.29 \\
(2.35)\end{array}$ & $<.0001$ & $<.0001$ \\
\hline
\end{tabular}

Note. ${ }^{*}$ From Wilcoxon rank sum test; ${ }^{\#} P$-value for time point $\times$ treatment arm, i.e., whether BPSI versus SOC difference differs at 6 and 12 months.

Given the fact that there are over 3 million long-term breast cancer survivors in United States, focusing on "survival" may be the wrong approach. There is no doubt that cancer survivors in general ${ }^{[27-30]}$ and breast cancer survivors in particular ${ }^{[24,31,32]}$ face several issues pertaining to "quality" as opposed to "quantity" of life that could be positively impacted by psychosocial interventions. These issues include body-image concerns, difficulties in tolerating treatment side-effects, lack of compliance, social isolation, and lack of emotional support - all of which can directly hamper re-assimilation of survivors in society as productive members. ${ }^{[33,34]}$ The BPSI program that clearly impacted QoL by 1 year post intervention in the current report has several advantages: First, it is based on the predictable sequence of feelings, thoughts, and behaviors that are universal to all humans going through a life-changing event. Second, it provides a structured program incorporating audio, visual, and kinesthetic learning styles, which is reproducible in a variety of healthcare settings. Third, it involves co-survivors (family, friends or other care-givers) thereby addressing the entire social network important to the survivor. A very important serendipitous advantage is the provision of common vocabulary for communication amongst the entire healthcare team - patients learn to interpret their feelings and behav- iors and are able to use appropriate language and skills to communicate and overcome the emotions and move on to the next stage. There was not much intergroup difference in QoL at 6-months; interestingly, the lack of difference was attributable to both groups showing improvement in QoL life score. This is understandable on two levels: one, QoL scores at baseline reflect the immediate impact of learning the diagnosis which are likely to improve over time, and two, patients in the SOC group are also expected to go through the change cycle albeit at their own natural pace. It is important to note in Table 2 that the even though both groups improved over six months, the standard of care group scores actually dropped below baseline at 1-year. The widening of gap between QoL scores at 1 year and maintaining statistical significance highlights the impact of intervention over and above the natural adjustment, even after adjustment for initial QoL and relevant baseline characteristics. In addition, many people without the knowledge and skills to move through the predictable phases of change may be vulnerable to get trapped in the "danger zone" between stage 3 and 4 (see Figure 1) and have poor QoL as a result. This study clearly demonstrated that the difference in QoL at 1 year expanded remarkably between the two groups. We believe that this impact is attributable to the survivors' skills at identifying the 
precise feelings, thoughts and behaviors as they go through treatment, ability to communicate with friends, family, and providers in a coherent fashion, and exploring their options in a rational manner which allows them to re-gain control and minimize helplessness in themselves and their providers and social network. It is noteworthy that literature varies on association of coping skills and outcome depending on design and outcome measured in a given trial. Davis et al. tested the efficacy of a psychosocial group intervention based on "Cancer Survival Toolbox" in African American cancer survivors and reported no decrease in distress, no improvement in psychosocial functioning or QoL. ${ }^{[35]}$ Akechi et al. report that breast cancer survivors' problem-solving skills are significantly inversely associated with Hospital Anxiety and Depression Scale. ${ }^{[36]}$ A cross-sectional survey on association between mental health and communication amongst families of breast cancer survivors found that open and productive communication amongst breast cancer survivors and their families was associated with better mental health. ${ }^{[37]}$ The only other report we found on a coping skills program focusing on self-efficacy and control that assessed the impact on QoL is the Pilars4life program; ${ }^{[38]}$ this program involved virtual meetings with a certified instructor weekly over a 10 week period. At 3- and 6-month follow-up, mean scores improved on measures of depression (Patient Health Questionnaire), anxiety (Generalized Anxiety Disorder), post- traumatic stress (Posttraumatic Stress Disorder Checklist), fatigue (Functional Assessment of Chronic Illness TherapyFatigue), and well-being (Functional Assessment of Cancer Therapy-General) from baseline (all $P<.01$ ). The important difference between the pillars4life study and current report is the control group. Our study documented that at 6 months, the QoL improved in the SOC arm as well rendering the difference between BPSI arm and SOC arm insignificant. No long-term outcome is reported on pillars4life program. "The Change Cycle TM" model in the current paper is compared with the control group and demonstrates a significant advantage over 1 year; we hope to conclude the study at 2-year time point. This program is highly cost-effective, is scalable beyond cancer survivors, and can be offered by nurse navigators or lay navigators with appropriate training. It focuses on the premise of change management and can therefore be utilized in a variety of healthcare settings such as newly diagnosed diabetics, hypertensive and other chronic conditions that need significant coping skills to maintain quality of life.

\section{ACKNOWLEDGEMENTS}

The David and Nona Payne Foundation provided funding for this research.

\section{CONFLICTS OF INTEREST DisClosure}

Authors have no conflict of interest.

\section{REFERENCES}

[1] Institute NC. 2014. http://cancercontrol.cancer.gov/ocs /statistics/definitions.html Accessed 2/25/2015.

[2] Rowland JH, Hewitt M, Ganz PA. Cancer survivorship: a new challenge in delivering quality cancer care. Journal of Clinical Oncology: official journal of the American Society of Clinical Oncology. 2006 Nov 10; 24(32): 5101-4. PMid:17093270. http: //dx.doi.org/10.1200/JC0.2006.09.2700

[3] DeSantis CE, Lin CC, Mariotto AB, et al. Cancer Treatment and Survivorship Statistics, 2014. CA: a cancer journal for clinicians 2014 Jul-Aug; 64(4): 252-71. PMid:24890451. http://dx.doi.o $\mathrm{rg} / 10.3322 /$ caac .21235

[4] Garfinkel L, Boring CC, Heath CW, Jr. Changing trends. An overview of breast cancer incidence and mortality. Cancer. 1994 Jul 1; 74(1 Suppl): 222-7. PMid:8004590. http://dx.doi.org/10.1002/c ncr. 2820741304

[5] De Angelis R, Tavilla A, Verdecchia A, et al. Breast cancer survivors in the United States: geographic variability and time trends, 2005-2015. Cancer. 2009 May 1; 115(9): 1954-66. PMid:19248047. http://dx.doi.org/10.1002/cncr. 24217

[6] Brinton LA, Sherman ME, Carreon JD, et al. Recent trends in breast cancer among younger women in the United States. Journal of the National Cancer Institute. 2008 Nov 19; 100(22): 1643-8. PMid:19001605. http://dx.doi.org/10.1093/jnci/djn344
[7] Kappel ML. It's not the model that matters-still lost in transition Journal of oncology practice / American Society of Clinical Oncology. 2013 May; 9(3): 128-9. PMid:23942488. http://dx.doi.o rg/10.1200/JOP. 2013.001016

[8] Baars JE, Bleiker EM, van Riel E, et al. Active approach for breast cancer genetic counseling during radiotherapy: long-term psychosocial and medical impact. Clinical Genetics. 2014 Jun; 85(6): 524-31. PMid:24372530. http://dx.doi.org/10.1111/cge.12335

[9] Fallowfield L, Jenkins V. Psychosocial/survivorship issues in breast cancer: are we doing better? Journal of the National Cancer Institute. 2015 Jan; 107(1): 335. PMid:25432407. http://dx.doi.org/10. 1093/jnci/dju335

[10] Mayer DK, Nekhlyudov L, Snyder CF, et al. American society of clinical oncology clinical expert statement on cancer survivorship care planning. Journal of Oncology Practice / American Society of Clinical Oncology. 2014 Nov; 10(6): 345-51. PMid:25316025. http://dx.doi.org/10.1200/JOP. 2014.001321

[11] Forsythe LP, Alfano CM, Leach CR, et al. Who provides psychosocial follow-up care for post-treatment cancer survivors? A survey of medical oncologists and primary care physicians. Journal of Clinical Oncology: official journal of the American Society of Clinical Oncology. 2012 Aug 10; 30(23): 2897-905. PMid:22778322. http://dx.doi.org/10.1200/JC0.2011.39.9832

[12] Cho J, Jung SY, Lee JE, et al. A review of breast cancer survivorship issues from survivors' perspectives. Journal of Breast Cancer. 2014 
Sep; 17(3): 189-99. PMid:25320616. http://dx.doi.org/10.40 48/jbc.2014.17.3.189

[13] Eakin EG, Strycker LA. Awareness and barriers to use of cancer support and information resources by HMO patients with breast, prostate, or colon cancer: patient and provider perspectives. Psychooncology. 2001 Mar-Apr; 10(2): 103-13. PMid:11268137. http: //dx.doi.org/10.1002/pon.500

[14] Nekolaichuk CL, Cumming C, Turner J, et al. Referral patterns and psychosocial distress in cancer patients accessing a psycho-oncology counseling service. Psycho-oncology. 2011 Mar; 20(3): 326-32. PMid:20878858. http://dx.doi.org/10.1002/pon.1765

[15] Salerno A. 2014. http://2014. changecycle.com/

[16] J.H. R. Office of Cancer Survivorship. 2014.

[17] Cella DF, Tulsky DS, Gray G, et al. The Functional Assessment of Cancer Therapy scale: development and validation of the general measure. Journal of Clinical Oncology: official journal of the American Society of Clinical Oncology. 1993 Mar; 11(3): 570-9. PMid:8445433.

[18] Brady MJ, Cella DF, Mo F, et al. Reliability and validity of the Functional Assessment of Cancer Therapy-Breast quality-of-life instrument. Journal of Clinical Oncology: official journal of the American Society of Clinical Oncology. 1997 Mar; 15(3): 974-86. PMid:9060536.

[19] Pocock SJ, Assmann SE, Enos LE, et al. Subgroup analysis, covariate adjustment and baseline comparisons in clinical trial reporting: current practice and problems. Statistics in Medicine. 2002 Oct 15; 21(19): 2917-30. PMid:12325108. http://dx. doi .org/10.1002 /sim.1296

[20] Fitzmaurice GM LN, Ware JH. Applied longitudinal analysis. New York: Wiley. 2004.

[21] Chuang-Stein C, Tong DM. The impact and implication of regression to the mean on the design and analysis of medical investigations. Statistical Methods in Medical Research. 1997 Jun; 6(2): 115-28. PMid:9261911. http://dx.doi.org/10.1191/0962280976710 68522

[22] Spiegel D. Mind matters in cancer survival. Psycho-oncology. 2012 Jun; 21(6): 588-93. PMid:22438289. http://dx. doi .org/10.10 02/pon. 3067

[23] Spiegel D. Minding the body: psychotherapy and cancer survival. British Journal of Health Psychology. 2014 Sep; 19(3): 465-85. PMid:23980690. http://dx.doi.org/10.1111/bjhp.12061

[24] Mustafa M, Carson-Stevens A, Gillespie D, et al. Psychological interventions for women with metastatic breast cancer. The Cochrane database of systematic reviews. 2013; 6: Cd004253. http://dx.doi.org/10.1002/14651858.cd004253.pub4

[25] Coyne JC, Thombs BD, Hagedoorn M. A meta-analysis of psychosocial interventions for cancer patients gone awry. Annals of behavioral medicine : a publication of the Society of Behavioral Medicine. 2009 Feb; 37(1): 94-6; author reply 97-100.

[26] Coyne JC, Hanisch LJ, Palmer SC. Psychotherapy does not promote survival (Kissane et al., 2007): now what? Psycho-oncology. 2007 Nov; 16(11): 1050-2. PMid:17937383. http://dx.doi.org/10. 1002/pon. 1285

[27] Konski A, Desilvio M, Hartsell W, et al. Continuing evidence for poorer treatment outcomes for single male patients: retreatment data from RTOG 97-14. International Journal of Radiation Oncology, Biology, Physics. 2006 Sep 1; 66(1): 229-33. PMid:16814950. http://dx.doi.org/10.1016/j.ijrobp.2006.04.005

[28] Richardson JL, Shelton DR, Krailo M, et al. The effect of compliance with treatment on survival among patients with hematologic malignancies. Journal of Clinical Oncology: official journal of the American Society of Clinical Oncology. 1990 Feb; 8(2): 356-64. PMid:2299375.

[29] Kuchler T, Bestmann B, Rappat S, et al. Impact of psychotherapeutic support for patients with gastrointestinal cancer undergoing surgery: 10-year survival results of a randomized trial. Journal of Clinical Oncology: official journal of the American Society of Clinical Oncology. 2007 Jul 1; 25(19): 2702-8. PMid:17602075. http://dx.doi.org/10.1200/JC0.2006.08.2883

[30] Valdes-Stauber J, Vietz E, Kilian R. The impact of clinical conditions and social factors on the psychological distress of cancer patients: an explorative study at a consultation and liaison service in a rural general hospital. BMC Psychiatry. 2013; 13: 226. PMid:24053562. http://dx.doi .org/10.1186/1471-244X-13-226

[31] Chilcot J, Norton S, Hunter MS. Cognitive behaviour therapy for menopausal symptoms following breast cancer treatment: Who benefits and how does it work? Maturitas. 2014 May; 78(1): 56-61. http://dx.doi.org/10.1016/j.maturitas . 2014.01.007

[32] Reynolds P, Boyd PT, Blacklow RS, et al. The relationship between social ties and survival among black and white breast cancer patients. National Cancer Institute Black/White Cancer Survival Study Group. Cancer Epidemiology, Biomarkers \& Prevention : a publication of the American Association for Cancer Research, cosponsored by the American Society of Preventive Oncology. 1994 Apr-May; 3(3): 253-9.

[33] Hennessy EM, Stevinson C, Fox KR. Preliminary study of the lived experience of exercise for cancer survivors. European Journal of Oncology Nursing: the official journal of European Oncology Nursing Society. 2005 Jun; 9(2): 155-66.

[34] Fernandez C, Fraser GA, Freeman C, et al. Principles and Recommendations for the Provision of Healthcare in Canada to Adolescent and Young Adult-Aged Cancer Patients and Survivors. Journal of Adolescent and Young Adult Oncology. 2011 Apr; 1(1): 539. PMid:23610731. http://dx.doi.org/10.1089/jayao. 2010. 0008

[35] Davis C, Rust C, Choi S. A pilot randomized study of skills training for African American cancer survivors. Social Work in Public Health. 2014; 29(6): 549-60. PMid:25144697. http://dx.doi.org/10. $1080 / 19371918.2014 .892865$

[36] Akechi T, Momino K, Yamashita T, et al. Contribution of problemsolving skills to fear of recurrence in breast cancer survivors. Breast Cancer Research and Treatment. 2014 May; 145(1): 20510. PMid:24682677. http://dx.doi.org/10.1007/s10549-0 14-2929-3

[37] Mallinger JB, Griggs JJ, Shields CG. Family communication and mental health after breast cancer. European Journal of Cancer Care. 2006 Sep; 15(4): 355-61. PMid:16968317. http://dx.doi.org/1 $0.1111 / j .1365-2354.2006 .00666 . x$

[38] Smith SK, O'Donnell JD, Abernethy AP, et al. Evaluation of Pillars4life: a virtual coping skills program for cancer survivors. Psychooncology. Jan 28, 2015. http://dx. doi .org/10.1002/pon. 375 0 